\title{
Application of mathematical modelling when determining the parameters effect of biomass densification process on solid biofuels quality
}

\author{
Peter Križan ${ }^{1, *}$, Michal Svátek ${ }^{1}$, Miloš Matúš ${ }^{1}$, and Juraj Beniak ${ }^{1}$ \\ ${ }^{1}$ Institute of Manufacturing Systems, Environmental Technology and Quality Management, Faculty of \\ Mechanical Engineering, STU in Bratislava, Nám. Slobody 17, 81231 Bratislava, Slovakia
}

\begin{abstract}
The main aim of this paper is to present the design of experiment (DOE) and evaluation methodology for this experimental plan in order to determine the parameters effect of biomass densification process on final solid biofuels quality. One of the recovery possibilities for waste biomass raw materials is production of solid biofuels. Using a variety combination of influencing variables can be improve the final quality of solid biofuels. Raw biomass material variables influence, especially (type of raw material, particle size, moisture content, compression pressure and compression temperature) can be recognized during the production of solid biofuels. Their effect can be seen through the quality indicators; especially mentioned variables significantly influence the mechanical quality indicators of solid biofuels. In this experimental research authors would like to investigate properties and behaviour of wood raw waste biomass during densification. This contribution discusses the analysis and design of experimental process, its individual steps and their subsequent DOE leading to the development of a mathematical model that will describe this process. This paper also presents the research findings regarding the effect of influencing variables on final density of solid biofuels during densification. Aim of the experimental process is to determine the mutual interaction between solid biofuels density and influencing variables during densification. Effect of compression pressure, compression temperature, moisture content and particle size on solid biofuels density from wood sawdust was determined.
\end{abstract}

\section{Introduction}

The densification process is a very interesting, but very complicated process, because many parameters effect the process and also the quality of the final solid biofuels. Solid biofuels quality is given by EU standards [1], and is evaluated by mechanical and chemical-thermic indicators of quality [2]. The properties of the raw material as well as technological demands are both very important during the solid biofuels production process [3]. The input raw material needs to be reduced to the optimal particle size, to dry to optimal moisture content level and we have to provide optimal technological parameters throughout the process of densification [4]. Each type of raw material requires an independent approach. Each small

*Corresponding author: peter.krizan@stuba.sk 
change in the properties of the raw material can influence the final quality of the solid biofuels $[5,6]$. Different raw material properties cause different conditions during the densification process [7]. The quality of solid biofuels is determined by the end-user's requirements on the heating system and the handling properties [8]. Low-quality pellets can cause operational problems in combustion systems, including undesired effects in the equipment such as slugging, fouling or corrosion, and may originate substantial amounts of gaseous and particulate matter (PM) emissions $[9,10]$. In this contribution variables influencing the slid biofuels quality were specified and assigned.

The general purpose of this paper is to design a series of experiment and their evaluation methodology that can allow to determine the influencing variables effect. When the correct methodology and methods are used the increase of solid biofuels quality can be ensured. According to designed experimental plan we will be possible to develop a mathematical model which will describe a related variables interaction and variables effect on final biofuels quality. This mathematical model can be useful at optimizing of densification process related to an input raw material. Obtained research findings can increase the environmental responsibility with the environment protection.

\section{Experimental plan}

Design of experiment should to clearly define the general aim of experiment, experiment conditions, controllable variables, experiment levels, treatment, noise, replication and evaluation [11].

\subsection{Experiment conditions}

The main aim of our experiment is to determine the effect of raw material variables on final density of solid biofuels. The best way is to choose such variables which have during the densification process continuous characteristics. As an inputs variables is necessary to choose those variables in where the effect on outputs are expected. This may not be clear at the beginning of the experiment and then is needed to realize a screening experiment. In our case, according to the recent published research $[12,13]$ works and our experience determination of the mutual interaction between biofuels density $(\rho)$, compression pressure $(P)$, compression temperature $(T)$, particle size $(L)$ and moisture content $(W r)$ of raw sawdust used for densification were chosen.

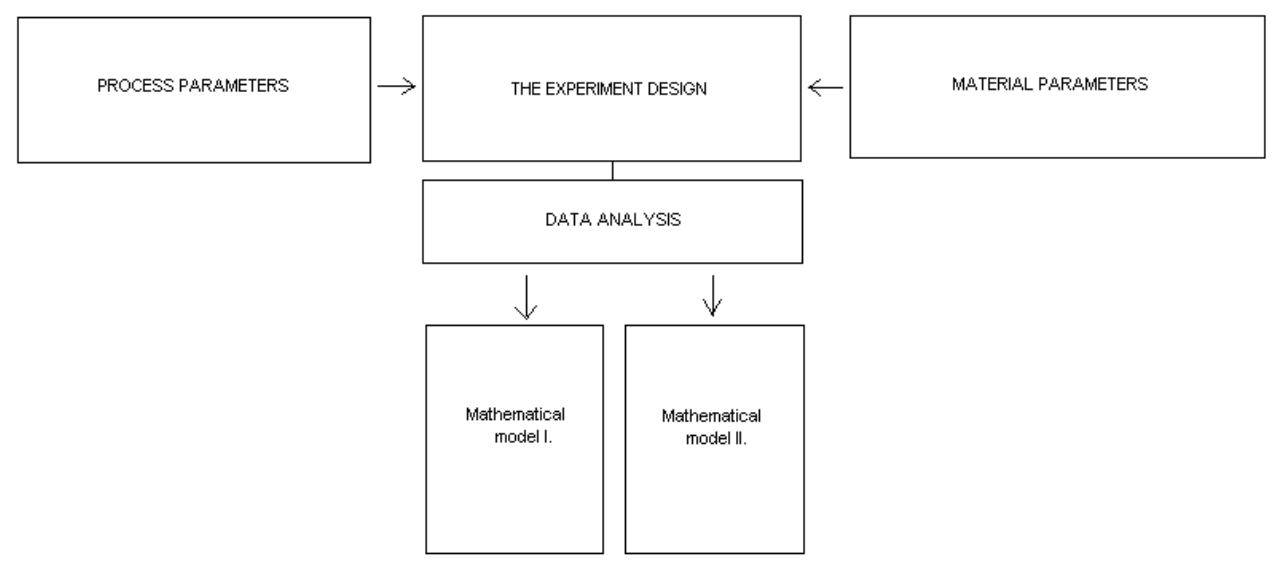

Fig. 1. A simplified diagram of the whole process [3]. 
With respect to the complexity of the presented process and the number of considered variables, 2 parameters of the process itself and 2 main material parameters, we have used second-order nonlinear model [11]:

$$
w_{i}=a_{0}+\sum_{j=1}^{k} a_{i} \cdot t_{j i}+\sum_{j=l}^{k=j} \sum_{l=j+1}^{k} a_{j i} \cdot t_{i j} \cdot t_{i i}+\ldots \ldots .+\sum_{j=1}^{k} a_{j j} \cdot t_{j}^{2}
$$

where

$w_{i}$ is $i$-times measured value,

$a_{0}, a_{i} \ldots . a_{k k}$ are unknown parameters,

$t_{l i}, t_{2 i}, \ldots, t_{j i}$ are individual variables or their interactions.

Second-order models are used if the models of first-order do not describe the examined object sufficiently. Compared to the model of first-order, the experiment with second-order model is more complex, involve fact on more levels and therefore also higher number of measurements. Each variable within the second-order experiment must be changed on at least three levels. Currently there is a high number of second-order proposals based on various criteria and presenting various characteristics.

If we consider a system that has 4 parameters, the output variable can be considered as a function with 4 variables $\rho=f(P, T, W r, L)$. Then we will consider this function in shape [3]:

$$
\rho=b_{0}+b_{1} \cdot P+b_{2} \cdot P^{2}+b_{3} \cdot T+b_{4} \cdot T^{2}+b_{5} \cdot W r+b_{6} \cdot W r^{2}+b_{7} \cdot L+b_{8} \cdot L^{2}
$$

where

$b_{i}$ are regression parameters,

$P, T, W r, L$ are controllable variables.

Then for the estimation of regression function coefficients is valid [3]:

$$
\hat{b}=\left(x^{T} x\right)^{-1} x^{T} \rho
$$

where

$\hat{b}$ is a estimates vector of unknown parameters of polynom,

$x$ is the matrix of the plan,

$\rho$ is the vector of the measured density values.

In this relation (3), the weight of individual measurements is not taken into account, so we extend the relationship by a covariance matrix. The previous relation (3) goes into the shape [3]:

$$
\hat{b}=\left(x^{T} U^{-1}(\rho) x\right)^{-1} x^{T} U^{-1}(\rho) \rho
$$

where the vector $\hat{b}$ has the form [3]:

$$
\hat{b}=\left(\begin{array}{c}
b_{0} \\
b_{1} \\
\cdot \\
\cdot \\
b_{8}
\end{array}\right)
$$

The design matrix $x$ has the form [3]: 


$$
x=\left(\begin{array}{ccccccccc}
1 & P_{1} & P_{1}^{2} & T_{1} & T_{1}^{2} & W r_{1} & W r_{1}^{2} & L_{1} & L_{1}{ }^{2} \\
1 & P_{2} & P_{2}^{2} & T_{2} & T_{2}{ }^{2} & W r_{2} & W r_{2}{ }^{2} & L_{2} & L_{2}{ }^{2} \\
\cdot & \cdot & \cdot & \cdot & \cdot & \cdot & \cdot & \cdot & \cdot \\
\cdot & \cdot & \cdot & \cdot & \cdot & \cdot & \cdot & \cdot & \cdot \\
\cdot & \cdot & \cdot & \cdot & \cdot & \cdot & \cdot & \cdot & \cdot \\
1 & P_{m} & P_{m}{ }^{2} & T_{m} & T_{m}{ }^{2} & W r_{m} & W r_{m}{ }^{2} & L_{m} & L_{m}{ }^{2}
\end{array}\right)
$$

where the $m$ determines the number of measurements.

Vector $\rho$ has form: $\rho=\left(\begin{array}{c}\rho_{1} \\ \rho_{2} \\ \cdot \\ \cdot \\ \rho_{m}\end{array}\right)$

The $U(\rho)$ covariance matrix has the form [3]:

$$
U(\rho)=\left(\begin{array}{ccccccc}
u^{2}\left(\rho_{1}\right) & u\left(\rho_{1}, \rho_{2}\right) & u\left(\rho_{1}, \rho_{3}\right) & . & . & . & u\left(\rho_{1}, \rho_{m}\right) \\
u\left(\rho_{2}, \rho_{1}\right) & u^{2}\left(\rho_{2}\right) & u\left(\rho_{2}, \rho_{3}\right) & . & . & . & u\left(\rho_{2}, \rho_{m}\right) \\
\cdot & . & . & . & . & . & . \\
\cdot & \cdot & . & . & \cdot & . & . \\
\cdot & . & . & . & . & . & u\left(\rho_{m-1}, \rho_{m}\right) \\
u\left(\rho_{m}, \rho_{1}\right) & u\left(\rho_{m}, \rho_{2}\right) & u\left(\rho_{m}, \rho_{3}\right) & . & . & u\left(\rho_{m}, \rho_{m-1}\right) & u^{2}\left(\rho_{m}\right)
\end{array}\right)
$$

The result of composing the previous equations is calculation of the regression function parameters, with which we are able to gain the final shape of the regression function for further work.

\subsection{Design of experiment (DOE)}

In order that the experiment can be effectively and correctly realized, various tools are required that support both the creation and the manipulation of design-space descriptions [1317]. Design-space descriptions are therefore usually based on design of experiments. Densification process is often dependent on a relatively large number of variables. It is practically impossible to test every combination of variables during process development in order to determine the relevant correlations between the individual variables. DOE uses a minimal number of experiments to provide an empirical process model for the interrelationship between the control and disturbance variables in the process and the resulting product and process characteristics [15]. On the Figure 2 in general the methods of statistical design of experiments are displayed [16]. Fractional factorial designs (screening designs) provide the possibility of significantly reducing the number of experiments. Results from screening designs can also be transferred to a subsequent series of experiments with less investigated factors, known as response surface designs $[15,16,17]$. Response 
surface designs are used to determine and then optimize non-linear interrelationships [17].

In the following Table 1 the chosen levels for each variable (raw material and process parameters) can be seen. Mentioned monitored variables (outputs) according to the technical standards and experimental device possibilities should be chosen. Outputs should represent quality indicators and these variables should have also a function of comparative criterions.

In our case, more than 2 levels of variables were chosen, than we have to use the Central Composite Design (CCD). Second but also very important reason for choosing of CCD in our case is volition to use surface response method, where 3 levels of variables is necessary condition for surface response modeling. The surface response method is a tool to investigate the response of a variable to changes in a set of design or explanatory variables and helps to find the optimal method for the response as a measurable output of the our interest $[15,16]$.

Table 1. Input controllable variables of the process $[3,13]$.

\begin{tabular}{|c|c|c|c|c|c|}
\hline \multirow{2}{*}{$\begin{array}{c}\text { Number } \\
\text { of levels }\end{array}$} & $\begin{array}{c}\text { Levels } \\
\text { according } \\
\text { CCD plan }\end{array}$ & $\begin{array}{c}\text { Compression } \\
\text { pressure - } \\
\text { "P”' }\end{array}$ & $\begin{array}{c}\text { Compression } \\
\text { temperature - } \\
\text { "T" }\left({ }^{\mathbf{0}} \mathbf{C}\right)\end{array}$ & $\begin{array}{c}\text { Particle } \\
\text { size - “L” } \\
(\mathbf{m m})\end{array}$ & $\begin{array}{c}\text { Moisture } \\
\text { content - } \\
\text { "Wr" (\%) }\end{array}$ \\
\hline 1 & $-\alpha$ & 63 & 55 & $0-0.5$ & 5 \\
\hline 2 & -1 & 95 & 85 & $0.5-1.0$ & 8 \\
\hline 3 & 0 & 127 & 100 & $1.0-2.0$ & 10 \\
\hline 4 & 1 & 159 & 115 & $2.0-4.0$ & 12 \\
\hline 5 & $\alpha$ & 191 & 130 & $4.0<$ & 15 \\
\hline
\end{tabular}

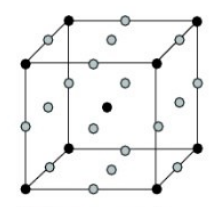

Full factorial

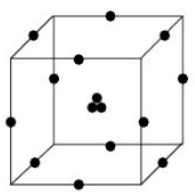

Box Behnken

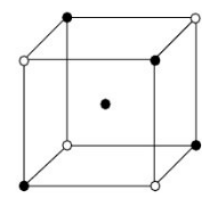

Fractional factorial

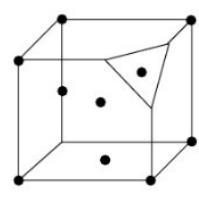

D-optimal design
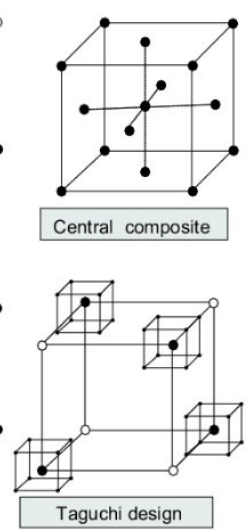

Fig. 2. Methods of statistical design of experiments [16].

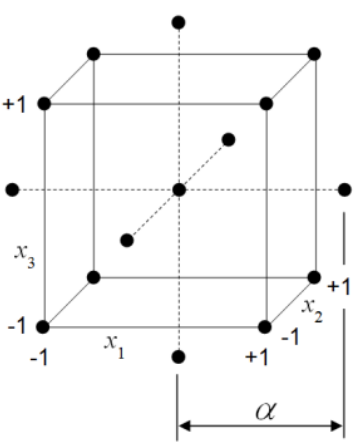

Fig. 3. Scheme of CCD plan [16].

The base of our CCD plan is two-level full factorial plan which is complemented by central and axial points. Value of number $\alpha$ and a number of central points on the base of other requirements (orthogonality, rotatability, number of variables, etc.), [11] related the CCD plan have to be calculated. On the Figure 3 can be seen the method by which can be $\mathrm{CCD}$ realized. In our case, due to the high number of examined variables and number of their levels we have decided for CCD of experiment consisting of three parts:

Core of design - is formed by factorial design $2^{k}$. If we want to reduce the number of measurements, the core can be used as reduced experiment $2^{k-p}$. For number of variables $k<4$ only complete experiment $2^{k}$ can be used as a core. For number of variable $5<k<7$ we use 
the complete experiment $2^{k}$ or the reduced experiment $2^{k-p}$ as a core. For number of variables $\mathrm{k}>7$ also reduced experiment $2^{k-2}$.

Axial points - points that are on the axes in distance of $\alpha>0$ from the centre of design. Their number is $n_{s}=2 k$.

Central points - points in the centre of the design. There are $n_{0}>0$ of central points. By suitable selection of " $\alpha$ " and the number of central points - " $n_{0}$," the proposals characteristics can be influenced. CCD for our case is presented in following Table. 2.

\subsection{Experiment realization}

A set number of samples for testing will be produced according to the designed experimental plan shown in Table 2. The testing and sample's production process should be randomize order to avoid the effects of systematic errors or we can increase the number of replications for a given setting of variables. Raw material for experiment has to be treated. Wood sawdust have to be separate for obtaining the given particle sizes and also have to be prepared for achieving the given moisture content level. Final samples were produced by experimental pressing stand . In the final, the outputs variables were measured by appropriate measuring equipment for final density obtaining. The values of measured parameters can be calculated as $\rho_{1}, \rho_{2}, \ldots ., \rho_{\mathrm{j}}$, where $j=1,2, \ldots, r$ (in our case, $\mathrm{r}=7$ ), for experiments $1 \mathrm{t}-16$. When evaluating, only measured values which characterize the core of the experiment for the centered composite design $2^{4}=16$ are used. From these measured values, the selection averages are calculated.

Table 2. Centered composite design with specific value of examined variables [3].

\begin{tabular}{|c|c|c|c|c|}
\hline $\mathbf{i}$ & $\mathbf{P}(\mathbf{M P a})$ & $\mathbf{T}\left({ }^{\mathbf{}} \mathbf{C}\right)$ & $\mathbf{W r}(\mathbf{\%})$ & $\mathbf{L}(\mathbf{m m})$ \\
\hline 1 & 95 & 85 & 8 & $0.5-1.0$ \\
\hline 2 & 159 & 85 & 8 & $0.5-1.0$ \\
\hline 3 & 95 & 115 & 8 & $2.0-4.0$ \\
\hline 4 & 159 & 115 & 8 & $2.0-4.0$ \\
\hline 5 & 95 & 85 & 12 & $0.5-1.0$ \\
\hline 6 & 159 & 85 & 12 & $0.5-1.0$ \\
\hline 7 & 95 & 115 & 12 & $2.0-4.0$ \\
\hline 8 & 159 & 115 & 12 & $2.0-4.0$ \\
\hline 9 & 95 & 85 & 8 & $2.0-4.0$ \\
\hline 10 & 159 & 85 & 8 & $2.0-4.0$ \\
\hline 11 & 95 & 115 & 8 & $0.5-1.0$ \\
\hline 12 & 159 & 115 & 8 & $0.5-1.0$ \\
\hline 13 & 95 & 85 & 12 & $2.0-4.0$ \\
\hline 14 & 159 & 85 & 12 & $2.0-4.0$ \\
\hline 15 & 95 & 115 & 12 & $0.5-1.0$ \\
\hline 16 & 159 & 115 & 12 & $0.5-1.0$ \\
\hline
\end{tabular}

In this par, the processing methods and evaluation of the experiment in general are described. Initial information about the effect of a particular variable is obtained mostly with the aid of the multivariation diagram. In a multivariation diagram, the maximum and minimum values of a certain group are shown. The variability in one group is characterized by a certain range that corresponds to the length of the segment connecting both points [14]. This diagram allows us to monitor level changes and variability at the same time. When the 
multivariation diagram indicates differences in averages and variability on several levels, it is possible to use statistical tests for further verification. Evaluating the divergence of averages in groups makes it possible to use procedures derived from the control chart average analysis (ANOM) or variance analysis (ANOVA) [16]. Both these methods assume normal distribution of the observed character and the same variability for some groups, which indicates an insignificant difference between selection distribution and range. The second of these assumptions verifies whether the Bartlett's test, typically used in relation with ANOVA or by the control diagram of range (R-diagram) or for variance $\left(\mathrm{s}^{2}\right.$-diagram), correspond by their character to ANOM.

Results of the experiment realized according to designed experimental plan also surface response can be used. Surface response will represent a group of points which forms a continuous surface when each axes in orthogonal view represents variables which influences the process and also the output variable $[15,17]$. Influence of two input variables are related to the third axes, which mainly represents the output variable. With this type of diagram can be monitored a behavior of output variable according to the changes of influencing (input) variables. On the Figure 5 can be seen a result response surface with values of variables. Color scaling is helpful and is used for better orientation when the maximum, minimum or transition is wanted.

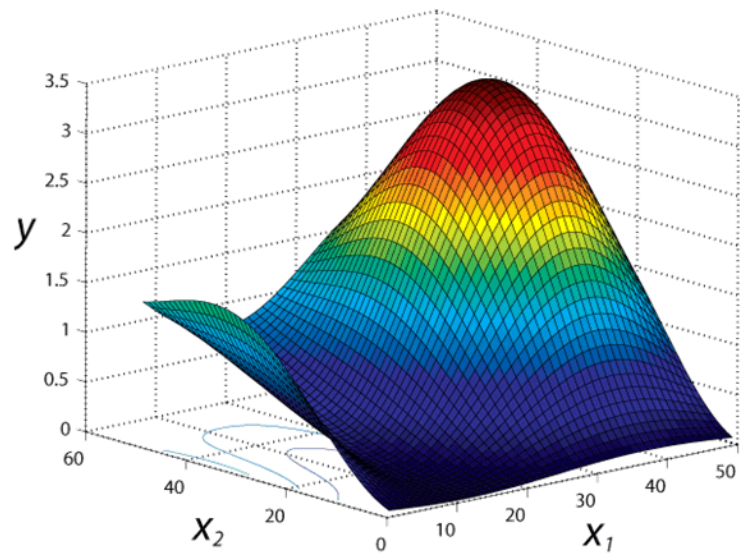

Fig. 4. Experiment result displayed through the surface response [15].

To we know create a surface response, it is necessary to have a "prescription" under which the points in a coordinate system will be bring out, in other words, a mathematical model that given us a three-dimensional function displayed as surface response will create. In nowadays for creation of mathematical models are various mathematical - statistics software widely used, which enable comfortable testing of hypothesis, testing of suitability of obtained data (values) and testing of model quality itself. With mathematical - statistics software can be generated many mathematical models, which described the process with some precision and can be chosen that model which suits us from variables composition and required precision points of view. We can find the optimal mathematical model from described points of view.

In our case multi-factorial analysis of variance (ANOVA) was used, because we have several input variables which influencing the process. ANOVA is used to compare and evaluate mean differences between two or more groups of variables on a single variable. Widely used mathematical - statistics software for all necessary analysis are e.g. JMP, Stat graphics, etc. This software can be used also in our case. Result of the mathematical statistics software is following model with factorial design

$$
y_{i j k l}=\mu+\alpha_{i}+\beta_{j}+\gamma_{k}+(\alpha \beta)_{i j}+(\alpha \gamma)_{i k}+(\beta \gamma)_{j k}+(\alpha \beta \gamma)_{i j k}+\varepsilon_{i j k l}
$$


where:

$\mu$ - is level constant,

$\alpha_{i}$ - is share of $i$-th level of variable $x_{l}$,

$\beta_{j}$ - is share of $j$-th level of variable $x_{2}$,

$\gamma_{i}$ - is share of $k$-th level of variable $x_{3}$,

$(\alpha \beta)_{i j}$ - is combined share of $i$-th level of variable $x_{l}$ and $j$-th level of variable $x_{2}$ (interaction), $(\alpha \gamma)_{i k},(\beta \gamma)_{j k},(\alpha \beta \gamma)_{i j k}$ - represents individual combined shares of given variables (their mutual interaction),

$\varepsilon_{i j k l}$ - is share of l-th observation (error).

\section{Evaluation and results}

The first step in evaluation is to perform an average analysis and test the variance equality hypothesis using Bartlett's test [18]. This test can be employed when differences between selection variances $S_{i}{ }^{2}$ or the range $R_{i}$ are insignificant. The results of Bartlett's test obtained using the program STATGRAPHIC S Plus is the value $P$ - the level of calculated significance, according to which the hypothesis $H_{0}$ is accepted or rejected on the level of specified significance $\alpha=95 \%$.

This means that, in order to accept the variance equality hypothesis, a value of $P$ larger than 0.05 is necessary [18]. The analysis results returned values of $P=0.55001$, which indicates that the hypothesis is acceptable. In this way, we satisfy one of the conditions for additional variance analysis using the method ANOVA. The selection can be regarded as homogeneous with respect to variability. This fact, based on the results, was also confirmed by the value of Cochran's tests.

The affecting factors are seen through the significant differences between selection averages $[18,19]$. This means that the fluctuation of the selection averages over the total average is larger than the fluctuation of each result within the selection. Variance analysis, contrary to selecting averages, compares two variance estimates describing the variability type. For this analysis, the same assumptions apply for the averaging analysis. The role of the variance analysis is to find the effect of one or more factors on the average value of independent, normally divided, random variables with the same variance. In the table for the ANOVA method (F values), for the defined significance $\alpha$, a certain number of degrees of freedom and critical value $F_{l-\alpha}$, are found. In another step, the ratio $S_{A}{ }^{2} / S_{e}{ }^{2}$ is compared with the critical value $F_{l-\alpha}$. If the value of the ratio $S_{A}{ }^{2} / S_{e}^{2}$ is larger than that of the critical value of $F_{l-\alpha}$, the effects of this factor are considered to be significant $[18,20]$.

Table 3. Variance analysis table- results.

\begin{tabular}{|c|c|c|c|c|c|c|}
\hline Variability source & $\begin{array}{c}\text { Sum of } \\
\text { squares }\end{array}$ & $\begin{array}{c}\text { Degrees } \\
\text { of } \\
\text { freedom }\end{array}$ & $\begin{array}{c}\text { Average } \\
\text { square }\end{array}$ & $\begin{array}{c}\text { Ratio } \\
\text { F }\end{array}$ & $\begin{array}{c}\text { Value } \\
\mathbf{P}\end{array}$ & Significance \\
\hline $\mathrm{A}-$ pressure „P“ & 0.0210523 & 1 & 0.0210523 & 3.40 & 0.0923 & 3. \\
\hline $\begin{array}{c}\mathrm{B}-\text { temperature } \\
\text { „T“ }\end{array}$ & 0.13857 & 1 & 0.13857 & 22.37 & 0.0006 & 1. \\
\hline $\mathrm{C}-$ moisture „Wr" & 0.0709649 & 1 & 0.0709649 & 11.46 & 0.0061 & 2. \\
\hline $\mathrm{D}-$ particle size „L“ & 0.0107137 & 1 & 0.0107137 & 1.73 & 0.2152 & 4. \\
\hline Residual & 0.0681389 & 11 & 0.00619445 & & & \\
\hline Sum & 0.30944 & 15 & & & & \\
\hline
\end{tabular}

For this analysis and the determination of each factor's significance, the program STATGRAPHIC S Plus was used once again. The analysis results are listed in Table 3. The effect of each parameter or its significance is given by the value of $P$-level of calculated significance, which we compared. The effect of the parameter is considered important at a 
significance level of $P^{*}(95 \%)$; when the value of $P$ is less than $(1-P *)$, this means $P<0.05$. From this, and based on the analysis results listed in Table 3 , it is implied that the order of significance for each of the parameters are as follows: compression temperature, raw material moisture content, compression pressure, particle size.

For a closer determination, not only of the effect of each parameter but also of their mutual interactions, a factor effect method can be used. The degree of influence of a factor on an observed variable is known as the factor effect, which is defined as the magnitude of response change caused by a change in the factor level. It is often referred to as the main factor effect, unlike the interaction effect. The magnitude of the main effects and their interaction are estimated. Estimated (calculated) values of each of the effects are shown in Table 4, and Figure 5 illustrates the effect differences.

Table 4. The effect value of each parameter and their interaction.

\begin{tabular}{|c|c|c|c|c|c|c|c|}
\hline B & $\mathrm{C}$ & BC & $\mathbf{A}$ & D & $\mathrm{ABC}$ & AC & AB \\
\hline 0.0465 & 0.0333 & 0.0254 & 0.0181 & 0.012938 & 0.012881 & 0.012065 & 0.008587 \\
\hline BCD & AD & ABCD & CD & ABD & ACD & BD & \\
\hline 0.00387 & 0.002897 & 0.002367 & 0.002005 & 0.000963 & 0.000661 & 0.000396 & \\
\hline
\end{tabular}

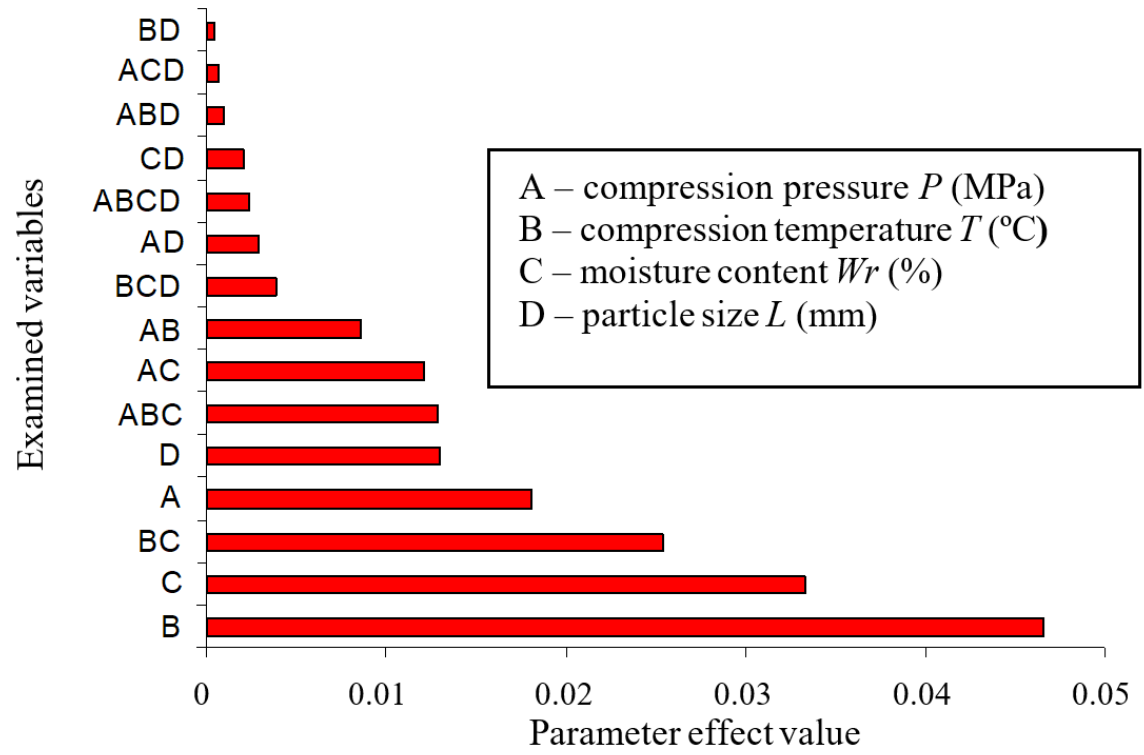

Fig. 5. Paret's effect diagram [21].

We supposed that the dependency is given by a continuous function of four variables $\rho=f(P, T, W r, L)$, which is expanded into a Taylor's series. A mode, which includes linear variables and the interaction of independent linear variables, is assumed. The model can be simplified into a functional dependence:

$$
\rho=f(A, B, C, D, A B, A C, A D, B C, B D, C D, A B C, A B D, A C D, B C D, A B C D)
$$

For a closer description of designing the model from the measured data, it is necessary to decide which of the variables in the relation (10) should be included in the model and which can be disregarded. Some variables have a negligible effect on the density (Figure 5) and can consequently be disregarded. A valid criterion is necessary to select use for the evaluation 
and comparison of variables in the model and regression model, respectively. Currently no theories exist that provide a precise specification of variables in a model. Nevertheless, there are several criteria that are suggested for use when selecting variable specifications for evaluating and comparing several regression models.

The next step was execution of selection of variables for mathematical model. For this selection we used three widely known criterions: index of multi-launching determination $\left(R^{2}\right)$, Akaike's criterion (AICc) and Root mean squared error criterion (RMSE) [3]. Based on the three previously described criteria, we will compare and evaluate the designed models with the variables. For the selection and evaluation of models, the software JMP 8 is used. This software calculates the values for each of the described criteria for each designed mode. With the aid of JMP 8, we have calculated the values for the observed criteria (Table 5). These three criteria indicate that Model 3 is the most accurate.

Table 5. The best models calculated with JMP 8 on the basis of the evaluating criterion.

\begin{tabular}{|c|c|c|c|c|c|}
\hline Model & Parameters & $\begin{array}{c}\text { Number of } \\
\text { parameters }\end{array}$ & $\mathbf{R}^{\mathbf{2}}$ & AICc & RMSE \\
\hline 1 & B,C,BC,A & 4 & $87.9 \%$ & -30.1238 & 0.058448 \\
\hline 2 & B,C,BC,A,D,ABC,AC & 7 & $96.8 \%$ & -24.8346 & 0.035139 \\
\hline $\mathbf{3}$ & B,C,BC,A,D,ABC,AC,AB & $\mathbf{8}$ & $\mathbf{9 9 . 3} \%$ & $\mathbf{- 3 2 . 7 9 9 6}$ & $\mathbf{0 . 0 1 7 7 6 4}$ \\
\hline 4 & C,AB,AC,BC,ABCD & 5 & $94.3 \%$ & -35.5702 & 0.041982 \\
\hline 5 & B,C,AB,AC,BC, ABCD & 6 & $96.1 \%$ & -33.239 & 0.036413 \\
\hline 6 & B, C, BC, A, D & 5 & $91.3 \%$ & -28.8272 & 0.05183 \\
\hline
\end{tabular}

We choose model with containing of all parameters and also with their most important mutual interactions (relation 11). This model had the best results after selection by criterions.

$$
\rho=f(A, B, C, D, A B, A C, B C, A B C)
$$

In the next phase we were able to design the mathematical model with help of software SAS and JMP 8 and also we were able to calculate or estimate the regression parameters values [21]. The final designed form of mathematical model you can see in following relation 12 , where the " $\rho$ " is solid biofuel density. This model is valid only for densification of pine sawdust and is valid only by variables levels listed in Table 1.

$$
\rho=e^{\left(\begin{array}{l}
4.98371-0.0261781 p-0.0410292 T-0.620594 w_{r}-0.015446 L+0.000228845 p \cdot T+ \\
0.0031851 p \cdot w_{r}+0.00528717 T \cdot w_{r}-0.0000273004 p . T \cdot w_{r}
\end{array}\right)}\left(\mathrm{kg} . \mathrm{dm}^{-3}\right)
$$

Then, using the designed mathematical model, according to (12), the density values at levels according to the experimental plan in (Table 2) were calculated and compared with the densities of the solid biofuels obtained from experiment at these configurations. 


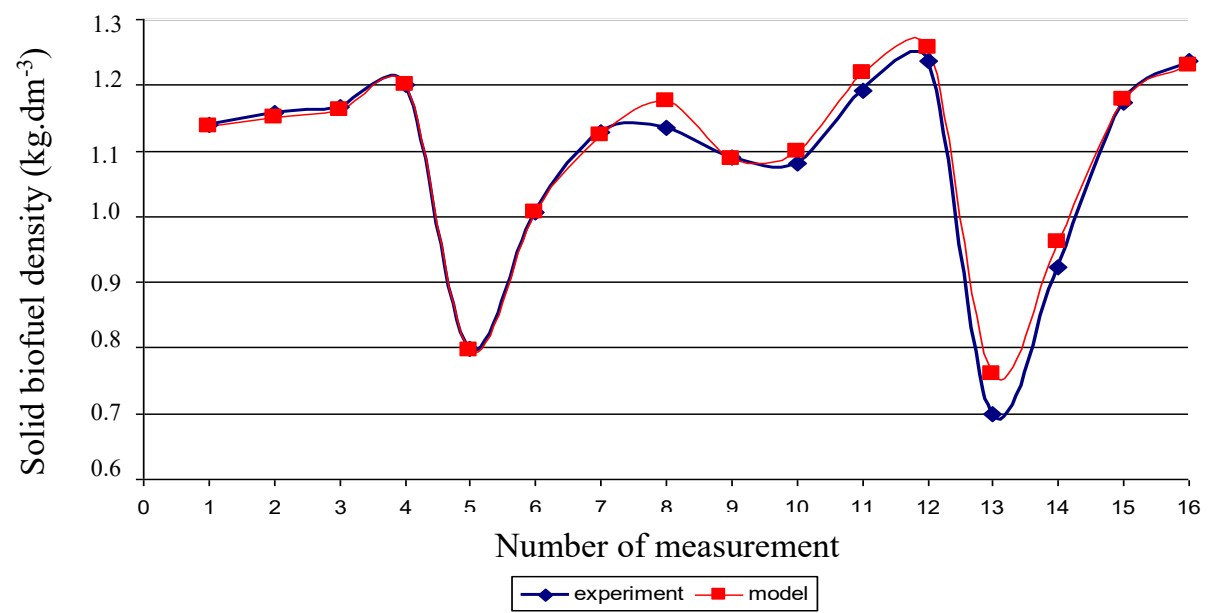

Fig. 6. Graphic comparison of solid biofuels densities obtained from experiment and calculated from the regression model.

If we want to look closely on the change of solid biofuel density, we have to use the "density response surface". Response surface is a great and useful tool for presenting the process in maximum amplitudes of individual parameters [21]. The result of experimental research can be presented in 2-axis interdependencies, but it is limiting to present the functionality with fixation of several parameters. Using the response surface we can get clear presentation of the process within the given extend by the means of surfaces $[21,22]$. These represent set-up levels. The following figure shows the effects of interacting compression pressure and temperature on the density of the biofuels from pine sawdust at various moisture content levels.
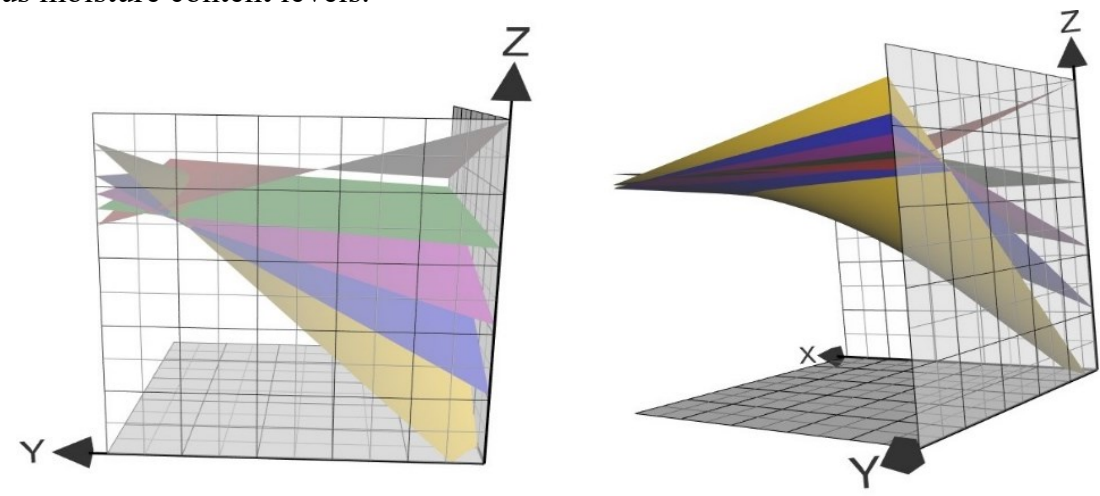

Fig. 7. Surface response of the density of biofuels from pine sawdust at a constant particle size / Labeling: $\mathrm{x}$-axis $\rightarrow$ compression pressure (MPa); y-axis $\rightarrow$ compression temperature $\left({ }^{\circ} \mathrm{C}\right)$; z-axis $\rightarrow$ biofuels density $\left(\mathrm{kg} \mathrm{dm}^{-3}\right)$; colour legend $\rightarrow$ levels of raw material moisture content: red $=5 \%$; green $=8 \%$; purple $=10 \%$; blue $=12 \%$; yellow $=15 \%$.

\section{Conclusion}

Design of experimental plan, methodology for evaluation of experimental research and research findings regarding the important variables effect during densification of pine sawdust was presented in this paper. Authors presented in detail process and methodology of 
DOE a evaluation process when the mathematical model have to be the final result. Presented mathematical-statistic methods are widely known, but the usage and application in this area is not usual. Presented research findings relates to the effect of material and densification process variables determination on final solid biofuels density. With application of mathematical and statistical methods we were able to design mathematical model of single axis densification of pine sawdust.

The main conclusions that can be drawn from this study are as follows:

- Applicability of mathematical and statistical methods was proven.

- All of the investigated input variables have an effect on monitored outputs.

- Compression temperature, raw material moisture content and mutual interaction of these two variables are most significant variables at densification of pine sawdust.

- The final solid biofuels density can be increased by a sensitive levels selection of influencing variables.

- Designed mathematical model can be used for prediction of solid biofuels density.

The paper is a part of the research done within the project VEGA 1/0420/16 - "Determination and research of parameters influence on final briquettes quality at waste biomass densification" funded by the Ministry of Education of Slovak Republic and to the Slovak Academy of Sciences, and also the paper was supperted by the project APVV-16-0485 "Biomass compacting tools cast from the advanced wear-resistant cast irons" funded by the Slovak Research and Development Agency."

\section{References}

1. EN ISO 17225-2:2014, Solid biofuels - Fuel specifications and classes - Part 2: Graded wood pellets, (2014)

2. R. Nosek, M. Holubcik, J. Jandacka, BioRes., 11, 44-53, (2016)

3. P. Križan, The densification process of wood waste, (De Gruyter open, 2015)

4. C. Serrano, E. Monedero, M. Lapuerta, H. Portero, F.Pro.Tech., 92, 699-706, (2011)

5. S. Mani, L.G.Tabil, S. Sokhansanj, Bio.Bio., 30, 648-654, (2006)

6. N. Kaliyan, R. Vance Morey, Bio.Bio, 33, 337-359, (2009)

7. P. Lehtikangas, Bio.Bo., 19, 351-360, (2001)

8. M. Baláš, M. Lisý, O. Štelcl, A.Pol., 52, 7-11, (2012)

9. P. Kracík, M. Balas, M. Lisy, J. Pospíšil, Mat. Teh., 50, 939-944, (2016)

10. M. Holubcik, J. Jandacka, M. Palacka, N. Kantova, E. Jachniak, P. Pavlik, Com.Scie.Let.Uni.Za, 19, 94-100, (2017)

11. B. Wortman, The Certified Six Sigma Black Belt Primer, (Quality Council of Indiana, 2001)

12. P. Križan, M. Matúš, L. Šooš, J. Beniak, Ener., 8, 6382-6398, (2015)

13. M. Matúš, P. Križan, Apl.-J.App.Math., 3, 87-96, (2010)

14. T.P. Ryan, Statistical Methods for Quality Improvement, (John Wiley and Sons, New York, 2011)

15. S.R. Schmidt, R.G. Launsby, Understanding Industrial Designed Experiments, (Air Academy Press, Colorado Springs, 1994)

16. A.J. Duncan, Quality Control and Industrial Statistics, (Richard D.Irwin, Inc., Reno, 1986)

17. T.H. Wonnacott, R.J. Wonnacott, Statistika pro obchod a hospodářství, (Victoria Publishing, a.s. Praha, 1993) (in Czech) 
18. R. Palenčár, I. Janiga, A. Horníková, J.M. Ruiz, Štatistické metódy v metrologických a skúšobných laboratóriách, (Publisher Ing. Peter Juriga, Bratislava, 2001) (in Slovak)

19. V. Chudý, R. Palenčár, E. Kureková, M. Halaj, Meranie technických veličín, (STU Bratislava, 1999) (in Slovak)

20. R. Palenčár, N. Jankura, Proceedings of 5th International Conference on Measurement 2005, (Smolenice, Slovak Academy Sciences, 2005)

21. P. Križan, L. Šooš, M. Matúš, J. Beniak, M. Svátek, W.Res., 60, 301-315, (2015)

22. P. Križan, M. Svátek, M. Matúš, M., Aplimat 2011. Proceedings. (Bratislava, FX s.r.o., 2011) 